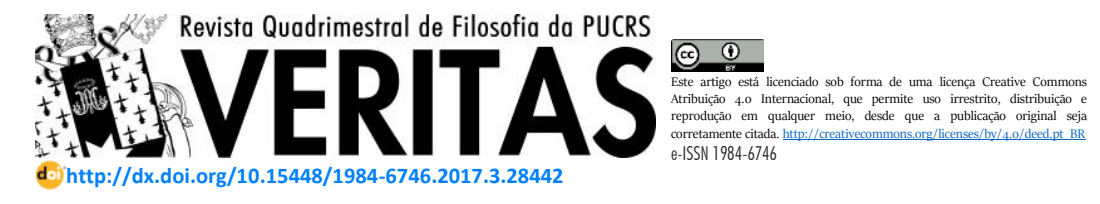

\title{
O que é agência epistêmica, afinal?
}

\author{
What is epistemic agency, after all?
}

Doraci Engel ${ }^{1}$

\begin{abstract}
RESUMO: Neste artigo examino a possibilidade de agência no domínio epistêmico a visão compartilhada por muitos filósofos de que possamos ser ativos, ao invés de passivos, em relação às nossas crenças e manifestações de conhecimento. Concluo que a noção de agência epistêmica é plausível apenas em sentido indireto, referindose as diferentes ações que realizamos com intuito de melhorar nossos compromissos epistêmicos. Trata-se de um tipo de agência prática, como qualquer agência, mas que não nos autoriza a pensar que possamos estar agindo de alguma maneira quando cremos ou conhecemos.
\end{abstract}

Palavras-chave: Agência; Racionalidade Epistêmica; Racionalidade Prática; Conhecimento.

ABSTRACT: In this paper, I examine the possibility of agency in the epistemic domain - the view shared by many philosophers that we can be active, rather than passive, in relation to our beliefs and knowledge. I conclude that the notion of epistemic agency is plausible only in an indirect sense, referring to the different actions we take to improve our epistemic commitments. It is a kind of practical agency, like any agency, which does not allow us to think that we can be acting in any way when we believe or know.

Keywords: Agency; Epistemic Rationality; Practical Rationality; Knowledge.

\section{Introdução}

A ideia de que atitudes epistêmicas, como crer, julgar, inferir e conhecer, envolvem algum tipo de ação de nossa parte é motivada fundamentalmente pela discussão sobre a natureza das normas epistêmicas. Desde John Locke, pelo menos, os conceitos epistêmicos fundamentais de justificação e conhecimento têm sido tratados em termos normativos. Obrigação intelectual, responsabilidade epistêmica, permissibilidade e garantia epistêmicas, entre outras, são expressões correntes no vocabulário epistemológico. E o que se pretende genericamente com a noção de agência epistêmica é conferir um status positivo a essas noções.

${ }^{1}$ PPGF/PUCRS < doraci.engel@gmail.com> 
Como estabelece o famoso princípio dever implica poder, parece ser um requerimento geral da normatividade que normas possam regular causalmente o comportamento dos agentes. De acordo com um certo paradigma metaético, acredita-se que somos epistemicamente responsáveis por nossas atitudes cognitivas da mesma forma (analogamente) como somos moralmente responsáveis por nossas ações. Foi assim na origem do debate, com William Clifford (1877) e William James (1896) e no âmbito das discussões sobre o voluntarismo doxástico e da ética da crença, nos anos de 1980. E é assim agora, quando boa parte do interesse epistemológico se volta para temas clássicos da filosofia prática e da filosofia da ação na expectativa de se encontrar um conceito unificado do que são razões normativas - o que determina que alguma coisa seja razão para outra.

A hipótese de que atitudes epistêmicas possam ter o mesmo tipo de explicação racional que se aplica à ação ou que possa haver uma forma genérica de explicação racional que se aplica tanto a atitudes epistêmicas como a ações enfrenta basicamente duas dificuldades. A primeira é de ordem metafísica: crer que $p^{2}$, conhecer que $p$, assim como julgar reflexivamente ou inferir que $p$ com base em $q$ são estados, não eventos ou processos. São verbos que denotam atividade mental, mas que não podem ser conjugados no modo continuo (de algo que acontece ao longo do tempo) como outros verbos de ação. ${ }^{3} \mathrm{E}$ a segunda dificuldade é de ordem normativa mesmo: a estrutura das razões que rege as atitudes epistêmicas contrasta crucialmente da estrutura das razões que governam a ação. Razões epistêmicas ostentam o que alguns autores, como Pascal Engel (2013), chamam de "unidade" que contrasta com a multiplicidade das razões práticas. Aparentemente qualquer razão (que atenda critérios mínimos de coerência e consistência) pode ser boa para agir, enquanto que

\footnotetext{
${ }^{2}$ Crenças, na definição tradicional que estou adotando aqui, são estados psicológicos que têm como objeto uma proposição. Já o termo "proposição" é definido como um objeto abstrato portador primário do valor de verdade compartilhável de várias atitudes mentais.

${ }^{3}$ Que atitudes tipicamente epistêmicas sejam estáticas do ponto de vista causal não quer dizer que elas não possam ser feitas por razões no sentido, por exemplo, de alguém que crê que $p$ porque ele crê que $q$. A diferença está na estrutura causal do porque. Crer que $p$ porque você crê que $q$ é uma relação de conteúdos proposicionais (uma relação de significado, portanto) e não de causação de um estado mental por outro. É uma explicação que cita apenas estados presentes. Como escreve Kieran Setiya: "Quando você crê que $p$ com base em $q$, sua crença é explicada pelo fato de que você crê agora que $q$. Seja qual for a explicação que está sendo empregada aqui, ela é diferente de uma que remete a crenças prévias, como quando você cré que $p$ porque você cria que $q$ " (Setiya 2013:182).
} 
somente razões baseadas na evidência suficiente da verdade da proposição são boas para crer ou, redundância à parte, conhecer.

\section{A concepção padrão de agência}

De acordo com uma versão familiar de agência, que estabelece as condições do que alguns chamam de agência humana por excelência (Velleman 1992, O'Brien 2007), um agente realiza uma ação, se ele faz $\phi$ intencionalmente, têm razões para $\phi$, pode ser reflexivamente consciente de $\phi$, é livre para $\phi$ e, assim, é responsável por fazer $\phi$. A essas condições costuma-se adicionar a exigência, conhecida como cláusula causal, de que a relação entre a intenção para fazer $\phi$ e a ação de fazer $\phi$ seja de causação pelos estados mentais do agente.

Em uma tentativa de oferecer uma taxionomia do que a literatura apresenta agora como agência epistêmica, Engel (2013) sumariza essa versão plena ou madura de agência (full-blown agency, na definição de Michael Bratman), nas seguintes condições mínimas: um agente faz $\phi$ se e somente se: i) ele tem uma razão para $\phi$ que é constituída pelo menos por uma intenção; ii) a razão e a intenção causam um movimento corporal de modo apropriado e iii) ele poderia ter agido diferentemente (possibilidades alternativas). ${ }^{4}$

A despeito dos problemas que o modelo acima pode apresentar há vários que o próprio Engel reconhece ${ }^{5}$-, penso que ele reflete adequadamente o que em geral se considera serem a concepção e a teoria padrão da ação. Trata-se de uma visão que concebe a ação em termos de intencionalidade (Anscombe 1957, Davidson 1963) e que explica a intencionalidade mediante uma teoria da ação em termos de causação pelos estados mentais do agente e eventos (Davidson 1963, 1981; Goldman 1970; Mele 2003).

\footnotetext{
4 Note-se que o sentido de fazer aqui é de fazer intencionalmente o que, conforme o modelo padrão de ação intencional que estou adotando neste trabalho, significa agir. De acordo com essa visão, o que racionaliza uma ação é a sua intencionalidade. Agir intencionalmente é o mesmo que agir racionalmente que, por sua vez, é o mesmo que agir. Assim, todas as referências ao termo ação neste trabalho dizem respeito a ação intencional e a ação racional.

5 O principal deles é o problema das cadeias causais desviantes. Como definir o que é modo apropriado, não desviante, sem incorrer em algum tipo de circularidade? Como explicar em que consiste causação não desviante sem apelar para alguma noção primitiva não analisável de agência ou controle? Davidson (1973) afirma que a teoria padrão da ação pode explicar apenas as condições necessárias para agência. Já Goldman (1970) argumenta que estabelecer a causação apropriada é uma questão empírica, que independe de qualquer assunção filosófica sobre o que é ser um agente.
} 


\section{Ação humana por excelência}

É comum que as condições (i)-(iii) sejam criticadas por serem muito exigentes. De fato, em um sentido muito amplo, o termo agência pode se empregar a virtualmente qualquer coisa ou entidade que tenha $o$ poder de causar alguma coisa (uma substância química, um terremoto, um termostato que aciona o motor de um refrigerador, por exemplo). Porém, o sentido de agência que interessa particularmente aos filósofos é bem mais estreito. Ele refere-se à ação humana, definida desde Aristóteles, pelo menos, como ação intencional, frequentemente consciente, autônoma e, em algum sentido, livre. ${ }^{6}$

A objeção certamente mais contundente às condições (i)-(iii) aponta justamente o contrário: a falta de certas exigências. Segundo alguns autores, como Harry Frankfurt e David Velleman, a teoria padrão da ação simplesmente não instancia a "ação humana par excellence", como define Velleman. Trata-se da ideia de que o modelo padrão de ação falha em capturar a participação do agente na ação, o que fica evidenciado especialmente no problema das cadeias causais desviantes. Muito resumidamente, é o problema de que sempre parece possível que os estados mentais relevantes e eventos causem o evento ou ação relevante (um certo movimento, por exemplo) de um modo que não corresponde à intenção do agente. As razões que causam a ação são diferentes da intenção. Como mostra o famoso exemplo de Davidson. O montanhista segura o companheiro de escalada na corda. O companheiro está solto no ar e há o risco de os dois despencarem. O montanhista avalia a situação e forma a intenção de se livrar do peso excessivo soltando a corda que os une. Esse pensamento o deixa nervoso e o nervosismo o faz soltar a corda (Davidson 1973). Vê-se aqui uma lacuna entre a intenção do montanhista e o seu comportamento. Seu comportamento não é causado por sua intenção seguindo a rota causal apropriada e, por isso, não pode ser considerado uma ação.

\footnotetext{
${ }^{6}$ Recentemente, o termo "agência" tem sido usado para designar propostas que, a rigor, não têm - ou não precisam ter - qualquer relação conceitual com o modelo padrão de ação adotado aqui. Esse é o caso, por exemplo, das teorias de agência coletiva (que se refere à ações de grupos), de agência relacional (que diz respeito a relações interpessoais e ao seu impacto causal na ação individual), de agência artificial (que explora a noção de ação na robótica e em sistemas de inteligência artificial), entre outras. Uma taxionomia atualizada sobre os diferentes tipos de agência disponíveis na literatura pode ser encontrada em Schlosser (2015).
} 
Nesta história [Velleman se refere à teoria padrão da ação em geral] razões causam uma intenção e uma intenção causa movimentos corporais, mas ninguém - isto é, nenhuma pessoa - faz qualquer coisa. Eventos psicológicos ocorrem dentro de uma pessoa, mas a pessoa serve apenas como arena para esses eventos. Ela não participa ativamente" (Velleman 1992: 461$).{ }^{7}$

De acordo com Velleman, o agente deve ser o "dono" das atitudes que causam a ação. ${ }^{8}$ E essa conexão, segundo ele, é um aspecto primitivo, não-analisável, do que é ser um agente. Contudo, propostas que descrevem um tipo de ação humana plena, nas quais o agente necessita possuir, exercitar ou instanciar certas propriedades cognitivas - ter consciência reflexiva, ser sensível a razões, ter controle racional sobre suas motivações etc - não são incompatíveis com as condições (i)-(iii). Elas revelam apenas que a teoria padrão não pode explicar o que é ser um agente pleno. Ou seja, as condições (i)-(iii) talvez não sejam suficientes para descrever esse tipo mais exigente de agência, mas ainda assim são necessárias, como aponta Davidson (1973).

\section{Razões para agir}

O que, de fato, parece ser decisivo para ideia de que somos agentes é que as ações devem ser causadas de modo certo pelo agente (devem estar conectadas apropriadamente à intenção do agente). E, antes disso, devem ser "intencionais sob alguma descrição" (Davidson 1980, ensaio 3). Para usar um outro exemplo de Davidson, a ação do cirurgião de atropelar o seu paciente com seu carro pode ter o efeito de remover o apêndice do paciente, mas não é uma ação sob a descrição remover o seu apêndice (Davidson 1980: 111). Fazer com que algo seja o caso é muito diferente de fazer algo. Do mesmo modo, prestar atenção a $p$, lembrar que $p$, aceitar que $p$, conjecturar sobre $p$, são ações mentais que podem ter o efeito de me fazer crer que $p$ ou conhecer que $p$, mas não são ações sob a descrição de crer que $p$ ou conhecer $p$.

\footnotetext{
${ }^{7}$ No original: "In this story, reasons cause an intention, and an intention causes bodily movements, but nobody that is, no person - does anything. Psychological events take place inside a person, but the person serves merely as the arena for these events: he takes no active part.”

${ }^{8}$ O significado da expressão "dono" aqui está relacionado com o problema das cadeias causais desviantes. O agente é "dono" da ação quando sua ação está alinhada de modo certo (não desviante) com a sua intenção. O que, segundo Velleman, exigiria um certo tipo de consciência primitiva do agente daquilo que ele está fazendo.
} 
Basicamente, o que o modelo padrão de ação nos ensina é que uma ação, para ser uma ação e não algo que apenas acontece conosco, deve ser racional. Ou seja, não basta que haja uma sequência causal de eventos que produz um certo movimento corporal. É preciso que o evento seja produzido por uma razão. É o que Davidson chama de intenção com a qual o evento é produzido que irá assegurar que a causação obedeça a rota certa. A ação deve se basear apropriadamente na razão pela qual ela é causada e não em qualquer razão disponível do agente.

Grande parte da atração da ideia de agência epistêmica deve-se às semelhanças na estrutura normativa de agir por razões e crer ou, redundância à parte, conhecer por razões. Vejamos, por exemplo, o caso da crença: uma crença, para ser justificada, deve ser baseada na razão apropriada, que não é qualquer razão, mas a razão que justifica a crença. Independentemente de tomarmos razões como estados mentais ou fatos, a relação "ser uma razão para x fazer $\psi$ " é aparentemente a mesma relação do que literatura epistemológica define como relação de suporte evidencial, no sentido de algo "ser uma razão para x crer que $p$ ".

De acordo com o modelo padrão da ação que estou assumindo aqui, agir intencionalmente é agir por uma razão. E agir por uma razão é agir de um modo que possa ser racionalizado pelas premissas de um silogismo prático, que consiste genericamente de uma premissa maior - a meta ou desejo do agente - e uma premissa menor - a crença de que determinada ação é o melhor meio para alcançar esse fim (Davidson 1970, 1980; Goldman 1970; Audi 1986).

Seguindo essa visão, o que racionaliza uma ação são as razões motivacionais e o movimento dessas razões para a ação, que são tratadas também como razões explicativas. ${ }^{9}$ Assim, razões motivacionais são concebidas como estados psicológicos do agente que tornam possível a explicação do que o agente está fazendo, no sentido de que podem ser citadas na explicação causal de sua ação. ${ }^{10} \mathrm{O}$ agente age porque ele tem um

\footnotetext{
${ }^{9}$ A questão de se explicar as ações intencionais como sendo as razões do agente para agir foi durante muitos anos um dos principais debates da filosofia da ação. Como já antecipei, minha escolha aqui é pelo modelo predominante. Nesta concepção, a explicação das razões da ação são explicações causais, que citam os desejos e as crenças meio/fim como as causas da ação (Goldman 1970).

${ }^{10}$ Para muitos, esta é a principal contribuição de Donald Davidson à teoria padrão da ação: razões motivacionais não são simplesmente causas, mas são causas racionais. Para que possam ser citadas na explicação causal de uma ação, as razões precisam estar relacionadas de modo apropriado (não desviante) com as motivações do agente. Para que seja uma ação intencional, ela precisa também ser produzida por uma razão, de tal modo que a razão em questão é a razão pela qual ela é produzida, assegurando-se assim que a causação tenha uma rota correta, não desviante. Em
} 
complexo desejo/crença que explica e motiva causalmente sua ação. Ou seja, as razões motivacionais são as únicas razões relevantes para a justificação ou racionalidade da ação.

É certo que razões epistêmicas, governadas pela evidência da verdade de uma proposição, podem justificar e assim fazer todo o trabalho explicativo de uma ação. Porém, apenas em um sentido indireto, como mostrarei ao longo deste trabalho. A literatura sobre racionalidade prática costuma fazer uma distinção entre razões explicativas e razões justificativas ou, conforme outra terminologia, entre razões motivacionais (que causam e explicam a ação) e razões normativas (que a justificam). Razões epistêmicas são razões justificativas ou mais controversamente normativas. Elas podem explicar a ação se o agente, todas-as-coisasconsideradas, de fato, as empregar na ação. A participação das razões epistêmicas na ação, no entanto, é indireta. Elas são razões pro tanto para $\phi .{ }^{11}$ São razões que falam a favor de $\phi$ e de se fazer $\phi$, mas podem não ser decisivas para motivar o agente. O balanço geral de suas razões poderá levá-lo a fazer diferente sem que ele incorra em qualquer tipo de irracionalidade.

Contrariamente as diferentes teorias voluntaristas de ação intencional, segundo as quais possuir metas ou intenções são atos da vontade, que não envolvem necessariamente a posse de estados mentais causalmente eficazes (Melden 1961, Ginet 1999, Sehon 2005), e de abordagens que explicam a ação intencional como sendo causada por certas propriedades intrínsecas, não redutíveis, do agente (Chisholm 1964, Taylor 1966, Lowe 2008), a teoria padrão assume que uma ação preenche os padrões normativos que se aplicam a ela apenas se ela preenche os padrões da racionalidade prática. E a racionalidade prática, de acordo com uma certa ortodoxia, endossada por autores como John Heil, Richard Feldman e Thomas Kelly, é diferente da racionalidade epistêmica, cujos requerimentos são neutros ou opacos em relação às razões contingentes sobre fatos do nosso sistema motivacional.

resumo, para que possa ser considerada uma ação, a ação deve seguir o padrão de racionalidade prática enunciado acima.

${ }^{11}$ Razões pro tanto são diferentes das razões meio-fim da ação intencional. Elas fazem parte de uma explicação normativa. Como define Broome (2013:53): “Uma razão pro tanto para $N$ (um sujeito qualquer) fazer $F$ (uma ação) é algo que desempenha o papel para $F$ (razão em favor de $F$ ) em uma explicação refletida de porquê $N$ deve fazer $F$, ou em uma explicação refletida de porquê $N$ não deve fazer $F[\ldots]$ ”. 
O que não quer dizer que razões epistêmicas sobre a verdade da crença de que $p$ com base na crença de que $q$ não possam ser incluídas nesses fatos. Ou, mais precisamente, que crenças sobre razões normativas em geral (epistêmicas ou não) não possam ter também um papel explicativo para criaturas racionais e, assim, motivar no agente a intenção ou o desejo relevante de ajustar suas atitudes a essas crenças. Quer dizer apenas que crenças normativas, que explicam por que agentes racionais devem ter determinados desejos e atitudes, não contam elas mesmas como razões motivacionais e, assim, não estão envolvidas na cadeia causal da agência. A menos, é claro, que elas representem efetivamente o desejo do agente de agir de acordo com elas. Mas, novamente, a relação aqui será indireta.

Nos casos paradigmáticos de racionalidade prática, razões normativas são fatos, aspectos do mundo, que contam a favor de agirmos de uma determinada maneira. Porém, podemos não estar conscientes desses fatos ou podemos estar conscientes e não sermos movidos por eles. $\mathrm{E}$, particularmente, podemos agir pela razão de que $p$ mesmo que $p$ não seja uma proposição verdadeira. Para agirmos basta que estejamos motivados, de modo não desviante, pela crença de que $p$ é meio para um fim, pouco importando a verdade ou falsidade da crença.

\section{O problema das razões certas e erradas}

Há várias características que diferenciam a racionalidade epistêmica da racionalidade prática. Do ponto de vista da ação, a mais relevante delas é a que envolve o papel do desejo, da vontade, indispensável na motivação (causal) da ação racional. Já do ponto de vista epistêmico, a diferença crucial reside nas regras de correção da crença que, como veremos a seguir, podem ser generalizadas para outros estados epistêmicos, como o conhecimento. Tradicionalmente, pensa-se que razões para querer crer, ou seja, motivadas pela vontade de crer, não são boas razões para crer. E isso parece ser assim, não só em decorrência da diferença na natureza da motivação, mas porque há também um contraste normativo entre o tipo de razão certa e o tipo de razão errada para crer. 
Uma crença é correta somente se ela for baseada em evidência suficiente ou, de acordo com outra visão, se e somente se ela for verdadeira. ${ }^{12}$

Uma junta de médicos conclui que o paciente está sendo acometido por uma doença grave que o levará à morte em poucos meses. O paciente tem uma razão para crer que irá morrer. Esta é a evidência (a razão epistêmica) que resulta do diagnóstico dos médicos. Mas ele também tem o desejo de não morrer e sabe-se objetivamente que manter uma atitude positiva diante da doença é uma excelente razão pragmática para que o paciente creia que irá se recuperar. Quais são as razões certas e erradas neste caso?

- Casos como este, em que razões pragmáticas parecem se sobrepor à razões epistêmicas, têm alimentado o debate sobre a distinção entre o tipo de razões certas e erradas para crer. Para alguns autores, como Derek Parfit (2011), essa distinção é vantajosa porque permite que se amplie a discussão sobre racionalidade para outras atitudes ou estados proposicionais, além de crenças. São atitudes que exibem as mesmas características da relação que razões pragmáticas têm com as crenças, como é o caso, por exemplo, da formação de intenções. ${ }^{13}$

Seguindo a terminologia de Parfit, o contraste entre razões práticas ou pragmáticas e razões epistêmicas ou teóricas pode ser melhor

\footnotetext{
${ }^{12}$ Para Mark Schroeder, a assimetria entre motivação para agir e motivação para crer é o que explica, por exemplo, por que parece mais difícil crer em Deus pelas razões pragmáticas de Pascal do que pelo argumento teológico de Anselmo. Ele observa que a razão que Anselmo nos oferece é epistêmica, ela pretende ser suportada diretamente pela evidência de Deus, enquanto que Pascal desenvolve um raciocínio indireto, que mesmo sendo bem-sucedido, parece não tornar a crença em Deus mais racional enquanto crença. Ela é mais racional enquanto ação (Schroeder 2012: 459).

${ }^{13}$ Um dos exemplos mais proeminentes da distinção entre razões do tipo certo e do tipo errado com relação a intenções é o quebra-cabeça da toxina, de Gregory Kavka (Kavka 1983). Trata-se de um experimento de pensamento sobre a possiblidade de se formar uma intenção para realizar uma ação que a pessoa não iria de fato realizar. $\mathrm{O}$ experimento tem a forma de um desafio: um bilionário excêntrico coloca diante de você uma toxina que, se você tomá-la, irá lhe causar um mal estar terrível por um dia, mas não irá ameaçar sua vida ou ter qualquer efeito residual. Ele irá lhe pagar um milhão de dólares amanhã pela manhã se, hoje, à meia-noite, você formar a intenção de tomar a toxina amanhã de manhã. Ele enfatiza que você não precisa tomar a toxina para receber o dinheiro. Você só precisa formar a intenção de tomar a toxina e você está inteiramente livre para mudar de opinião depois de receber o dinheiro. Eis a questão: é possível formar uma intenção e também intencionar mudar de opinião mais tarde? A resposta de Kavka é que não podemos intencionar o que não iremos fazer, pois isso envolveria uma inversão estranha na causalidade da ação. A intenção de receber o dinheiro só poderia atuar causalmente sobre a decisão de tomar a toxina caso o efeito [receber o dinheiro] pudesse afetar a causa [tomar a toxina] (Kavka 1983: 33-36). O que os filósofos observam com relação a esse caso é que, assim como na formação de crenças, há uma assimetria de motivação entre intencionar e agir. É mais difícil (impossível, talvez) formar uma intenção com base na motivação de ganhar uma recompensa desvinculada da ação, do que agir motivado pela recompensa. Trata-se de uma assimetria também de razões. Ela afeta a racionalidade da ação, mas não da intenção. Como intenções não podem ser formadas desvinculadas do seu objeto - a ação - formar a intenção de tomar a toxina para ganhar a recompensa, sem intencionar as consequências ruins, é uma tarefa provavelmente impossível.
} 
compreendido mediante uma distinção entre razões estado-relacionadas (razões dadas pelo estado mental do agente) e razões objeto-relacionadas (razões dadas pelo conteúdo que aquela atitude deve ter para que o agente possa ser tomado como racional). Pensa-se que razões do tipo certo para atitudes epistêmicas devem ser suportadas pelo objeto ou pela evidência e razões do tipo errado são aquelas baseadas apenas nos benefícios de se estar em um determinado estado de ter tal atitude (razões pragmáticas ou estado-relativas). ${ }^{14}$

Basicamente, o que Parfit argumenta é que a relação "ser uma razão para” entre os fatos sobre os objetos que desejamos e os desejos para os quais esses fatos são razão não pode ser reduzida a uma relação naturalista, como no modelo desejo-crença que prevalece na literatura da ação. Assim, eu somente tenho uma razão para realizar uma ação quando realizar essa ação traz como resultado que eu tenho uma razão de desejar esse resultado. Para Parfit, ter uma razão para agir é ter uma razão para desejar, que é dada não pelo estado mental (o desejo e a crença de que determinada ação é meio para realizá-lo), mas pelo resultado objetivo da ação. Trata-se de algo que é bom por si só, independentemente de ser bom ou desejado por alguma pessoa. ${ }^{15}$ A moral por trás da distinção, sugerida por Parfit, não é que razões epistêmicas, que correspondem ao que ele chama de razões objeto-relativas (relativas ao conteúdo alético da ação ou da atitude), são as razões do tipo certo e que razões pragmáticas relacionadas com o desejo ou com o estado mental em que o agente se encontra sejam do tipo errado. Sua sugestão é que a própria distinção entre racionalidade prática e racionalidade epistêmica é equivocada. Para ele, razões práticas (no caso aqui estado-relativas) simplesmente não parecem ser razões. Como escreve Engel:

\footnotetext{
${ }^{14}$ A observação intuitiva aqui é que o tipo certo de razão para crer é a evidência que $p$. E que, considerando que $p$ é o objeto da crença que $p$, o tipo certo de razão para crer é suportado pelo objeto do qual ela é razão para. Da mesma forma como no exemplo da toxina. O que dá errado com a ideia de formar a intenção de tomar a toxina é que o incentivo é ganhar a recompensa. Ou seja, a intenção não vem acompanhada da razão correspondente de realmente tomar a toxina, que é o tipo certo de razão para a ação. Ela simplesmente não é suportada pelo objeto do qual a intenção é razão para.

15 Na visão de Parfit, razões estado-relativas são razões "autointeressadas" (self-interested). Elas são razões que dizem respeito ao desejo de que certos eventos aconteçam para o nosso próprio bem prático. Essas razões podem ser usadas para definir o que é bom para nós. Porém, elas contrastam com as razões objeto-dependentes, que são razões “onipessoais”. Segundo Parfit, estas são as únicas razões normativas que nós todos temos para agir, considerando os eventos de um ponto de vista imparcial e impessoal. Ele conclui que razões onipessoais podem ser reconhecidas, pesadas e comparadas com nossas razões pessoais (estado-dependentes) da mesma perspectiva pessoal com a qual respondemos às razões pessoais vinculadas aos nossos autointeresses (Parfit 2011, seção 13).
} 
Posso desejar crer que $p$ e através de alguma rota desviante me causar a crença que $p$. Mas meu desejo para crer não pode ser uma razão genuína para crer. Apenas razões que são baseadas na minha suficiente evidência de que $p$ é verdadeiro podem ser razões. Meu desejo de ter uma crença que trará conforto, prazer ou alívio, por mais justificado que posso estar do ponto de vista prático ou prudencial, não pode ser uma razão genuína para crer (Engel 2013: 166). ${ }^{16}$

Porém, como observa também Engel, o fato que sempre parece ser possível que um desejo ou uma intenção tome uma rota desviante não quer dizer que somente razões para crer ou para intencionar são razões genuínas. ${ }^{17} \mathrm{Ou}$ seja, que razões pragmáticas para querer crer ou querer intencionar não são razões. Elas podem não ser as razões adequadas para crer ou conhecer, mas são perfeitamente boas para agir. ${ }^{18}$ Ao afirmar que um desejo é racional se as crenças sobre a base na qual ele é formado são fatos que seriam razões caso eles ocorram, Parfit se compromete com a tese de que só há um tipo de racionalidade, a racionalidade epistêmica. Trata-se de uma pressuposição. Ou, mais precisamente, de uma idealização que, como tal, somente pode fazer sentido em termos puramente procedurais (razões para agir seriam apenas aquelas razões fixadas por aquilo que o agente iria desejar se seus desejos fossem maximamente responsivos à evidência). Mas, em se tratando de razões para agir, que é o foco quando falamos de agência, isso é, no mínimo, controverso. Como escreve Jussi Suikkanen:

Se formarmos um conjunto substancialmente ruim o suficiente de desejos maximamente coerentes e consistentes, ainda assim não podemos

\footnotetext{
${ }^{16}$ No original: "I can desire to believe that $p$, and through some deviant route, cause myself to believe that $p$. But my desire to believe cannot be a genuine reason to believe. Only reasons which are based on my sufficient evidence that $p$ is true can be reasons. My desire to have a belief which will bring me comfort, pleasure or relief, as justified it can be from a practical or prudential point of view, cannot be a genuine reason to believe."

${ }^{17}$ É importante notar novamente que o problema das cadeias causais desviantes não tem uma resposta satisfatória na literatura. Mas isso não quer dizer que o quadro evento-causal, predominante na filosofia da ação, que explica nossas razões para agir em termos de razões estado-relativas, seja equivocado. Como observei anteriormente, ele pode ser insuficiente, mas ainda assim é necessário para explicarmos a ação intencional (ver Davidson 1980).

18 De acordo com a tradição, uma das características que distinguem razões epistêmicas de razões práticas ou pragmáticas é a exclusividade das razões epistêmicas. Razões epistêmicas respondem unicamente a verdade da evidência, enquanto que razões práticas responde a uma multiplicidade de fatores. Como escreve Timothy Scanlon: “desde que crer é crer que algo é verdadeiro, o único tipo de razão que alguém pode ter para crer - para sentir a convicção, emprega-la em pensamento posterior, e assim por diante, é uma razão para pensá-lo como verdadeiro (Scanlon 1998:35).
} 
garantir que a pessoa irá querer evitar um futuro de agonia. Se, pelo contrário, estipularmos que ninguém conta como inteiramente racional a menos que deseje evitar agonia no futuro, então estamos assumindo razões substanciais ao invés de usar a racionalidade para as razões que temos. Essa visão deixaria de ser uma visão baseada em desejos (Suikkanen 2009:5). ${ }^{19}$

O que Suikkanen quer dizer com o trecho acima é que razões para agir devem ser baseadas em desejos que representam efetivamente os estados mentais do agente e não em desejos ideais. E a tese comumente aceita aqui é uma que remete ao famoso dualismo de Henry Sidgwick (1874) que aponta para a incomensurabilidade entre razões práticas e epistêmicas. Conforme essa concepção, não há como comparar nossas razões para alcançarmos as coisas que são melhores para nós com nossas razões para alcançarmos o que é melhor de um ponto de vista objetivo, impessoal. Assim, em se tratando de ação, ou seja, de agência, agir sobre razões práticas ou sobre razões epistêmicas parece ser igualmente racional. Voltarei a este ponto mais adiante.

\section{Ações de conhecimento?}

É conhecido o esforço de alguns autores (Hawthorne e Stanley 2008, Williamson 2005 e Littlejohn 2014) de tentar unificar razões epistêmicas e razões práticas em torno do que a literatura consagrou como a norma do conhecimento. Resumidamente, essa norma diz o seguinte: "Quando a escolha de S é p-dependente é apropriado para S tratar a proposição que $p$ como uma razão para agir se e somente se $S$ sabe que $p$ " (Hawthorne e Stanley 2008). ${ }^{20}$

Do ponto de vista do modelo padrão de ação que estou assumindo neste trabalho, a tese de que para agir racionalmente é preciso conhecer enfrenta basicamente duas dificuldades. Primeiro, ela não é uma verdade normativa. Saber que $p$ não é necessário, nem suficiente para que seja permissível para $\mathrm{S}$ tratar a proposição que $p$ como razão para agir. E,

\footnotetext{
${ }^{19}$ No original: "If we make a substantially bad enough set of desires maximally coherent and consistent, we still cannot guarantee that the person will want to avoid a future of agony. If, in contrast, we stipulate that no-one counts as fully rational unless she desires to avoid future agony, then we are assuming substantial reasons instead of using rationality to account for what reasons we have. This view would no longer be a desire-based view".

${ }^{20}$ No original: "Where S's choice is $p$-dependent, it is appropriate for $\mathrm{S}$ to treat the proposition that $p$ as a reason for acting if and only if $\mathrm{S}$ knows that $p . "$
} 
segundo, ela não nos diz nada sobre a natureza da ação, sobre a suposta agência que ocorre quando exercitamos, instanciamos ou manifestamos o conhecimento prévio que $p$. Ações manifestando conhecimento podem ocorrer independentemente da influência de um item de conhecimento, seja esse item de conhecimento um estado mental primitivo, nãoanalisável, como sugere Timothy Williamson, ou um estado hibrido, como ensina a tradição. ${ }^{21}$

A chave para entender como a norma do conhecimento poderia unificar razões epistêmicas e razões práticas é a noção de ações de conhecimento. ${ }^{22}$ São ações que manifestam que $\mathrm{S}$ sabe que $p$, como asserir conscientemente, se mover conscientemente de uma determinada maneira, responder conscientemente a uma pergunta etc. Elas representam o que Gilbert Ryle (1949) classificou de ações inteligentes. São ações que manifestam conhecimento prático, um conhecimento-como, do mesmo tipo que está presente em atividades como tocar piano, ler um texto, escrever uma carta e assim por diante. Elas são inteligentes porque manifestam conhecimento proposicional, conhecimento de fatos ou conhecimento-que.

Todas as ações inteligentes são casos de conhecimento-que? Esta é a pergunta de Ryle. E sua resposta, como sabemos, é não. Algumas ações são realizadas inteligentemente (expressando, portanto, conhecimentoque) sem terem que ser guiadas por qualquer instância de conhecimentoque prévio. Um pianista talentoso pode executar uma nota especifica ao piano, sem que essa demonstração de conhecimento-como seja precedida ou governada por um conhecimento-que associado (como, por exemplo, conhecer objetivamente a inclinação correta dos dedos em relação às teclas, o ritmo, a força aplicada nas mãos etc.). Ele provavelmente adquiriu algum conhecimento-que quando apreendeu a tocar piano ou a executar essa nota especifica. Mas agora que ele já sabe, ele não precisará

\footnotetext{
${ }^{21}$ A maioria dos filósofos considera que o conhecimento é um estado hibrido, composto por um estado mental (crença) e por certas condições factivas não-mentais (ver Nagel 2013). A exceção, como apontei, é Williamson. Para ele, tentar oferecer uma análise conjuntiva do conceito "conhecer que" adicionando um conjunto mental (crer e alguma propriedade adicional) a um conjunto não-mental (verdade e talvez algum outro fator ambiental) é o principal problema da análise tradicional do conhecimento (Williamson 2000: 31). Não irei examinar aqui a intuição original de Williamson. Isto porque, de acordo com essa visão, conhecimento não pode ser uma ação e, assim, não pode ser um caso de agência como estou considerando aqui. Agência envolve necessariamente intenções, que são estados mentais por conta própria e, como tal, não podem produzir genuinamente um estado mental supostamente mais básico ou primitivo, seja ele qual for.
}

22 "Knowing actions", no original cunhado por Stephen Hetherington (2013). 
implementar esse conhecimento-que para executar a nota. Ele poderá inclusive ter desenvolvido sua própria técnica, sem que seus movimentos atuais tenham qualquer relação causal ou normativa com o conhecimentoque que um dia talvez ele tenha adquirido.

É importante notar que, quando filósofos como Jason Stanley e Williamson afirmam que toda manifestação de conhecimento-como é uma manifestação de conhecimento-que (Stanley e Williamson 2001), eles não estão se referindo a habilidades como tocar piano, andar de bicicleta, disparar uma flecha etc. Eles estão se referindo a habilidades cognitivas ou a "ações de conhecimento", como escreve Stephen Hetherington (2013). E, como ocorre com relação a qualquer ação, habilidades cognitivas como asserir, formular corretamente uma hipótese ou responder acuradamente a uma pergunta não envolvem (não precisam envolver) qualquer trabalho teórico prévio para concluirmos que tais ações manifestam conhecimentoque. Se aplicarmos a norma do conhecimento ( $r$ é razão para A fazer $x$ se e somente se A sabe que $r$ ), veremos que o conteúdo dessas ações é justamente o conhecimento-que que está sendo asserido, aceito ou expressado na nossa resposta.

Há, portanto, uma diferença entre ações inteligentes que são demonstrações de conhecimento-como e manifestações de conhecimentocomo que para serem inteligentes precisam ser instâncias de conhecimento-que. É esse segundo tipo de ação inteligente que está sob a mira da crítica anti-intelectualista de Ryle. Não irei explorar o argumento de Ryle aqui. Escrevendo na primeira metade do século passado, seu alvo não era o tipo de visão externalista sobre conhecimento-que que prevalece atualmente na literatura. O que ele pretendia mostrar - e mostrou, a meu ver - é que o componente da justificação no conhecimento-que não pode ser requerido coerentemente como parte do que está sendo gerado e, assim, constituir a inteligência dentro da ação inteligente. ${ }^{23} \mathrm{E}$ o seu raciocínio continua perfeitamente válido. Aqui está uma generalização do argumento de Ryle, desenvolvida por Hetherington:

\footnotetext{
${ }^{23}$ Na redução ao absurdo apresentada no segundo capítulo de "The Concept of Mind" (1949), Ryle nota que o que torna uma ação inteligente, distinta e superior a um comportamento de outra forma indistinguível é que a primeira, mas não a última, é "guiada por proposições regulatórias" que distinguem sua ação como inteligente. De tal modo que para que uma ação seja inteligentemente executada é preciso haver uma consideração prévia de uma proposição e a execução desta operação, ela mesma, pode ser mais ou menos inteligente, mais ou menos estúpida. Logo, agir inteligentemente requer uma operação prévia de considerar uma proposição e considerar uma proposição inteligentemente requer a ação prévia de considerar uma proposição. E, assim, sucessivamente.
} 
Suponha a título de redução que qualquer ação inteligente A apenas existe em parte porque existe alguma instância prévia $\mathrm{C}$ de conhecimento-que. Note que tal uso de C é uma ação, presumivelmente uma ação inteligente. Chame esta ação de A1. Então nossa assunção intelectualista inicial para a redução também se aplica a A1: deve ter havido uma instancia de $\mathrm{C}_{1}$ de conhecimento-que precedendo e supervisionando a generalização de A1. Agora este uso de C1 é uma ação inteligente - que podemos chamar de A2. E assim por diante até o infinito. Enfrentamos uma necessidade sem fim de várias ações pertinentes - A1, A2, A3, ... - para sequencialmente e conjuntamente constituir A. No entanto, ninguém pode realizar uma infinidade de tais ações - A1 (= usar C para gerar A), A2 (= usar C1 para gerar A1), A3 (= usar C2 para gerar A2) etc., como precursor para realizar até mesmo uma única ação inteligente A. Ainda assim, ações inteligentes são realizadas. Então, não é assim que elas são realizadas. Por redução, em outras palavras, nem toda ação inteligente, manifestando conhecimento-como, precisa ser precedida e supervisionada - se é para ela existir como uma ação inteligente - por algum conhecimento-que (Hetherington 2013: 26-7). ${ }^{24}$

Se o argumento de Hetherington estiver correto, como penso que está, então a tese de que existem "ações de conhecimento", no sentido de que há uma conexão normativa entre conhecimento e ação que pode ser unificada em torno da chamada norma do conhecimento, não é verdadeira. Ela não se aplica a ações inteligentes em geral. E também não se aplica a ações inteligentes em particular, como asserir que $p$, aceitar $p$, responder acuradamente que $p$ etc. Ela pode ser uma verdade normativa epistêmica que, no entanto, pode não ter qualquer repercussão sobre o raciocínio prático do agente. Pelo menos não uma repercussão direta. Como já assinalei, agir ou não com base em razões epistêmicas (que respeitem normas epistêmicas) é uma decisão prática. E o fato, por exemplo, de um agente realizar um ato de fala que não preenche os

\footnotetext{
${ }^{24}$ No original: "Suppose for reductio that any given intelligent action A exists only in part because it has been preceded and overseen (whether with awareness or not) by some already existing instance $\mathrm{K}$ of knowledge-that. Notice that such a use of $\mathrm{K}$ is an action, presumably an intelligent one. Call that action A1. Then our initial intellectualist reductio assumption applies also to A1: there needs to have been some instance K1 of knowledge-that preceding and overseeing the generation of A1. Yet this use of $\mathrm{K} 1$ is an intelligent action - which we may call A2. And so on, ad infinitum. We confront an unending need for various pertinent actions - A1, A2, A3, . - to have sequentially and jointly contributed to the constituting of A. However, no one can have performed an infinitude of such actions - A1 ( = using $\mathrm{K}$ to generate $\mathrm{A}$ ), A2 ( = using K1 to generate A1), A3 ( = using K2 to generate A2), etc. - as a precursor to performing even a single intelligent action A. Still, intelligent actions are performed. So, that is not how they are performed. By reductio, in other words, not every intelligent action, manifesting knowledge-how, needs to have been preceded and overseen - if it is to exist as an intelligent action - by some knowledge-that."
} 
padrões de correção da asserção (A deve asserir $p$ se e somente se A conhece $p$ ) não significa que ele não está asserindo alguma coisa.

De acordo com as condições (i)-(iii), listadas anteriormente, o que um agente precisa para tratar uma razão como premissa em seu raciocínio prático é ter uma crença justificada (que respeite certos requerimentos formais de coerência e consistência). O requerimento formal de coerência meios-fins é apresentado, em geral, da seguinte maneira: se um agente intenciona algum fim $\mathrm{F}$ em $t$ e ele crê em $t$ que intencionar $\mathrm{M}$ é um meio necessário para $\mathrm{F}$, ele deve intencionar $\mathrm{M}$ em $t$. Por exemplo, se intenciono ir ao cinema e creio que pagar o ingresso é um meio necessário para ir ao cinema, eu devo intencionar pagar o ingresso. A mesma estrutura se aplica também ao requerimento de consistência: se um agente intenciona algum fim F em $t$ e crê em $t$ que F e F' não podem ambos ser realizados, então ele não deve intencionar F' em $t$. Se crença de $\mathrm{S}$ de que $\mathrm{M}$ é meio para $\mathrm{F}$ é verdadeira e, assim, um caso de conhecimento, é uma outra questão. Do ponto de vista da correção do seu raciocínio, o que ele deve assegurar é que ele tem razões que justificam $p$ e que, se $p$ for verdadeira, ele sabe que $p$ é $\mathrm{M}$ para $\mathrm{F}$ e não que ele crê que sabe que $p$ é M para $\mathrm{F}$.

O que é tratar alguma coisa como razão para ação ou como premissa em um raciocínio prático? É mesmo necessário conhecer $p$ para agir com base em $p$ ? Eis aqui um caso apresentado por Jessica Brown (2008) que talvez esclareça melhor a questão:

Cirurgião: Um estudante está acompanhando o trabalho de um cirurgião por um dia. Pela manhã ele o observa examinando clinicamente um paciente A que tem uma doença no rim esquerdo. A decisão é remover o rim à tarde. Mais tarde, o estudante observa o cirurgião já na sala de cirurgia com o paciente A anestesiado na mesa de cirurgia. O cirurgião consulta os registros do paciente. O estudante está intrigado e pergunta uma das enfermeiras: "O que está acontecendo? Por que ele está olhando os registros do paciente? Ele esteve clinicando o paciente esta manhã. Será que ele não sabe qual é o rim que precisa ser operado?” E a enfermeira responde: "Claro, que ele sabe qual é o rim. Mas imagine o que seria se ele removesse o rim errado. Ele não deve operar sem antes consultar os registros do paciente" (Brown 2008: seção 3). ${ }^{25}$

\footnotetext{
${ }^{25}$ No original: "Surgeon: A student is spending the day shadowing a surgeon. In the morning he observes her in clinic examining patient A who has a diseased left kidney. The decision is taken to remove it that afternoon. Later, the student observes the surgeon in theater where patient A is lying anaesthetized on the operating table. The operation hasn't started as the surgeon is consulting the patient's notes. The student is puzzled and asks one of the nurses what's going on:
} 
A motivação de Brown é a mesma que move outros autores que defendem a chamada infiltração pragmática (estados epistêmicos são sensíveis ao risco prático da verdade ou falsidade da proposição). Para esses autores, em virtude da repercussão prática que a remoção do rim errado teria na saúde do paciente, o cirurgião deveria considerar a "rechecagem" antes de decidir. Em um sentido ordinário é exatamente assim que as coisas acontecem. Porém, a discussão interessante aqui é se o cirurgião deveria ou não considerar a "rechecagem" como premissa no seu raciocínio prático, considerando que este aspecto prático afeta a verdade da proposição. Será que afeta? Como? E se o cirurgião falhasse em reconhecer a necessidade de "rechecagem" como premissa? Sua crença inicial (justificada) de que ele sabe que $p$ seria irracional e, assim, ele não poderia usá-la como razão para agir?

É fácil reconhecer que o cirurgião teria sido tremendamente negligente se não considerasse a necessidade de "rechecagem" no seu raciocínio prático (afinal, verificar os registros do paciente antes de uma cirurgia faz parte do protocolo médico). E isso certamente é razão para ele agir de acordo com o protocolo. Porém - e aqui está o ponto -, esta não é uma razão epistêmica, no sentido de que ele deve tratar o protocolo como razão evidencial para crer justificadamente e, assim, saber qual é o rim que deve ser operado.

Em resumo, como antecipei, razões para agir não exibem a mesma estrutura normativa das razões para crer ou conhecer. Tratar razões práticas como um tipo de razão epistêmica talvez faça sentido se atribuirmos certas propriedades metafísicas à relação entre conhecimento e ação. Mas que propriedades poderiam ser essas, senão as propriedades causais de um estado mental prévio causando outro estado, como no modelo padrão de ação descrito acima? No caso especifico da norma do conhecimento, essa conexão, para não ser ociosa, teria que assegurar que o conhecimento, já presente, constitui as ações de conhecimento e, assim, permite que uma ação seja conhecível. Mas diante de uma reivindicação substancial desse tipo, como superar a carga cética, apontada por Ryle e Hetherington? Como defender, sem circularidade, o princípio de que

Student: 'I don't understand. Why is she looking at the patient's records? She was in clinic with the patient this morning. Doesn't she even know which kidney it is?'

Nurse: 'Of course, she knows which kidney it is. But, imagine what it would be like if she removed the wrong kidney. She shouldn't operate before checking the patient's records.” 
qualquer ação será uma ação de conhecimento se e somente se o agente tem o conhecimento que a ação manifesta?

\section{O problema das razões certas e erradas, novamente}

Uma alternativa talvez mais promissora para se unificar razões epistêmicas e razões práticas seja considerar as razões objeto-relativas ou epistêmicas, reguladas pelas normas da crença ou do conhecimento, como um tipo razão para agir (razões estado-relativas ou práticas). Para alguns autores, como Hetherington, as atitudes de crer e conhecer são constituídas inteiramente pelas habilidades do agente de agir intencionalmente. Contra Williamson, Hawthorne e Stanley, ele sugere que o conhecimento-que é apenas um tipo de conhecimento-como, sendo as razões estado-relativas (práticas) as únicas razões genuínas que nós realmente temos.

Noções centrais da epistemologia, como crença justificada (racional) e conhecimento, podem ser "ressignificadas" de uma perspectiva inteiramente "praticalista", como a sugerida por Hetherington ${ }^{26}$ ? Podemos nos referir coerentemente a esses conceitos independentemente das normas epistêmicas que são exatamente o que assegura que algo possa ser uma crença justificada ou um caso de conhecimento, em primeiro lugar?

Questões como essas são o combustível para um tipo forte de pragmatismo que corresponde, como antecipei, ao ambiente conceitual talvez mais promissor para se falar genuinamente em agência epistêmica. A tese pragmatista aqui não é a da comensurabilidade epistêmica, sugerida, por exemplo, por Richard Foley (1993), de que em muitos casos as razões práticas para crer podem se sobrepor e determinar, digamos assim, as razões epistêmicas. ${ }^{27}$ Ela é mais forte do que isso. Ela sugere que as normas epistêmicas relevantes são normas práticas, a medida em que estão presentes (são parte) da racionalidade prática. Assim, por exemplo, a distinção entre

\footnotetext{
${ }^{26}$ O termo "praticalista" se refere especificamente a um tipo de revisão à análise tradicional do conhecimento, proposta por Hetherington. Penso ele pode ser generalizado para outras propostas, como a John Hyman ((1999), que tomam o conhecimento como tipo direto de ação.

${ }^{27}$ De acordo com Foley, em alguns casos, todas as coisas consideradas pode ser racional para um individuo crer o que não é epistemicamente racional que ele creia. E um exemplo disso, segundo ele, é o controvertido caso do estudante zeloso: ele está bem preparado, conhece a matéria e tem razões para crer que irá passar no exame final. Porem como uma lição de humildade, os professores desenvolvem um mecanismo que altera automaticamente a prova, tornando-a tremendamente mais difícil, se ele pensar que irá passar no exame. Ou seja, por conta de um mecanismo prático que é capaz de antecipar suas crenças, o estudante não pode crer aquilo que ele tem boa evidência [dominar a matéria, ter passado em todas as provas anteriores etc.] (Foley 1991:99).
} 
tipos certos ou errados de razões para atitudes epistêmicas não pode ser estabelecida pela distinção entre razões epistêmicas (dadas pelo objeto da atitude) e razões práticas (dadas pelo estado mental). Todas as razões seriam de um único tipo: seriam razões práticas ou estado-relativas. Como escreve Mark Schroeder:

Exatamente como você pode querer ir para a praia, você pode querer que Jack vá à praia. Assim, ao invés de assumir que 'querer' é polissêmico ou ambíguo entre essas duas construções, linguistas assumem que 'querer' tem o mesmo significado e estrutura sintática, mas que em 'você quer ir à praia' há um pronome silencioso entre 'querer' e 'para'. Nesta visão, para a qual há evidência adicional da sintaxe, 'você quer ir para a praia' significa aproximadamente 'você quer a si mesmo para ir para a praia' - e é por isso porque tomamos desejos (quereres) como tendo objetos proposicionais, mesmo quando eles são desejos sobre o que fazer (Schroeder 2012: 463). ${ }^{28}$

Basicamente o que Schroeder pretende dizer na citação acima é que o slogan de que o tipo certo de razão são razões suportadas pela evidência objeto da crença é falso. Isto porque desejos tomam proposições como seus objetos, da mesma forma como qualquer atitude epistêmica. O problema, segundo ele, é que não há como definir, sem algum tipo de arbitrariedade, por que razões suportadas pelo objeto da crença (a evidência de que irei para a praia) e da intenção (a ação de ir à praia) são do tipo certo, enquanto razões suportadas pela evidência do desejo ou pelo estado mental do agente são do tipo errado? Ele argumenta que todas as características (crer com base na evidência de que eu irei à praia e intencionar com base na crença de que irei para a praia) estão presentes também nas atitudes que resultam do estado mental do agente.

Schroeder afirma que existem razões dadas pelo estado mental do agente que são razões certas para adotar atitudes e não apenas para não as adotar. Especificamente, ele sustenta que pode haver razões do tipo certo estado-relativas para não intencionar ou não crer. Para usar o exemplo do próprio Schroeder: pode ser racional para um agente não

\footnotetext{
${ }^{28}$ No original: "Just as you can want to go to the beach you can want Jack to go to the beach. So rather than assuming that 'want' is polysemous or ambiguous between these two constructions, linguists assume that 'want' has the same meaning and syntactic structure, but that in 'you want to go to the beach' there is a silent pronoun between 'want' and 'to'. On this view, for which there is additional evidence from syntax, 'you want to go to the beach' means approximately, 'you want yourself to go to the beach'-that's why we take desires (wants) to have propositional objects, even when they are desires about what to do. And the same evidence goes for intention.”
} 
intencionar ir para a praia se ele está esperando uma previsão mais detalhada do tempo. Ele pode refrear por um instante o desejo de ir à praia.

Segundo Schroeder, o fato de nós termos esse tipo de controle sobre razões estado-relativas mostra que a distinção entre razões estadorelativas e razões objeto-relativas é equivocada. Ele argumenta que as razões certas neste caso não envolvem necessariamente o objeto da intenção, que é a ação de ir à praia, nem o objeto da crença, que é a evidência de que estou indo à praia. Assim como também poderia ser uma razão do tipo certo para o paciente não crer (não assentir) a proposição da junta médica de que ele irá morrer em poucos meses, conforme indicam os exames e toda evidência clínica. A razão do paciente para não crer ou suspender o juízo é dada por seu estado psicológico. Ele quer crer que ele não irá morrer. Só que há um detalhe: crer que ele não irá morrer também pode ser uma razão do tipo certo objeto-relativa, pois sabe-se empiricamente que manter uma atitude positiva diante da doença pode ajudar na recuperação.

Para Schroeder, entretanto, todas as razões nesses casos são razões práticas. Elas consistem nos custos e benefícios das atitudes em questão. De tal modo que razões epistêmicas ou objeto-relativas seriam apenas uma subclasse de razões estado-relativas. Assim, como Bratman (1987), para quem nós exercemos uma espécie de autogovernança epistêmica quando planejamos nossas ações para o futuro, Schroeder também pensa que normas epistêmicas são importantes para manter nossas ações alinhadas com nossas intenções para o futuro.

Elas são normas de racionalidade prática (basicamente as normas de consistência e de coerência meios-fins, a que me referi acima ) que funcionam como premissas no raciocínio do agente sempre que ele delibera sobre seus planos. São normas que "nos permitem coordenar e controlar nossas próprias ações através do tempo (ou de coordenar nossas próprias ações com as ações de outros agentes) e, de tomar decisões, às vezes em que temos mais recursos cognitivos disponíveis" (Schroeder 2012:483).

Na sua visão, são os benefícios que a verdade traz para o raciocínio prático (é melhor raciocinar com base em premissas verdadeiras do que falsas) que explica porque a evidência é uma razão do tipo certo. Mas explica também porque, quando as razões evidenciais são de algum modo 
inconclusivas - o diagnóstico dos médicos compete com o efeito que uma atitude positiva do paciente pode ter sobre a evidência -, suspender o juízo ou evitar formar uma determinada crença também pode ser um tipo certo de razão.

É importante notar, entretanto, que desde que Foley introduziu o debate sobre comensurabilidade epistêmica na literatura contemporânea há um relativo consenso de que razões para abster-se de crer ou para não formar uma intenção são diferentes de razões para não crer ou não intencionar. E este é um fato que o próprio Schroeder parece reconhecer. Ele nota que refrear a intenção de fazer A não é apenas uma questão de ausência de intenção em relação a A. É uma atitude positiva, da mesma forma como evitar crer que $p$ não é a ausência de crença, mas uma atitude positiva de buscar ou esperar mais evidência sobre $p$.

Desde que refrear seja uma atitude, a teoria objeto-relativo/estado-
relativo pode se aplicar a razões para ela, afinal - o tipo certo de razões
apresentado no meu argumento acabará sendo o de razões que têm seu
suporte no objeto da suspensão de juízo ao invés de no objeto da crença"
(Schroeder 2012:476). ${ }^{29}$

Schroeder ressalva, entretanto, que a distinção entre razões certas e erradas para crer ou intencionar somente fará sentido se admitirmos que pode haver um estado de razões, cujo objeto é a suspensão da crença que é diferente do objeto da crença. E por que não haveria esse estado? Do ponto de vista da tradição, que trata como evidência aquilo que é percebido sensorialmente pelo indivíduo, considerando a totalidade das suas experiências presentes, razões para suspender a crença de que $p$, podem ser razões prudenciais que decorrem do estado psicológico de insegurança em que o sujeito se encontra em relação ao mérito prático da evidência (Feldman 2000).

Porém, o fato de haver tal estado, em que o sujeito está emocionalmente dividido entre crer no diagnóstico médico e o desejo de crer que ele irá se recuperar, não quer dizer que o objeto dessas atitudes seja diferente. Ambos envolvem razões evidenciais para não crer que $p$, que, no entanto, são diferentes quando a atitude é evitar a crença de que $p$ por

\footnotetext{
${ }^{29}$ No original: "Since withholding is an attitude after all, the object-given/state-given theory can apply to reasons for it after all - the right-kind reasons featured in my argument will simply turn out to be reasons which bear on the object of withholding rather than on the object of belief."
} 
evidência insuficiente e quando a atitude é não crer $p$ por que esta é a evidência. Ou seja, o fato de haver um estado aparentemente comum de razões para não crer que $p$ e não querer crer que $p$ não anula a distinção entre razões práticas e epistêmicas. A razão do paciente suspender o juízo em relação ao diagnóstico médico e adotar uma atitude positiva diante da doença não deixa de ser uma razão evidencial.

É importante notar que mesmo que a decisão do paciente de adotar uma atitude positiva nesse caso não fosse uma boa razão epistêmica (não é verdade que atitudes positivas diante da doença auxiliam na recuperação), ainda assim o raciocínio do paciente ao suspender o juízo sobre o diagnóstico continuaria sendo governado pela evidência. Ele não assentiu ao diagnóstico dos médicos porque ele estava psicologicamente inseguro e, assim, não tinha evidência suficiente de sua verdade.

O que é, de fato, próprio da distinção entre razões objeto-relativas e razões estado-relativas é que ela se aplica a atitudes epistêmicas e não à ações. E isso é assim mesmo que essas ações tenham motivação e fins epistêmicos, como é o caso tipicamente da investigação ou de qualquer atividade deliberativa ou de decisão racional que tenha como objetivo descobrir ou estabelecer a verdade sobre $p$. Olhando sob esta perspectiva, vê-se que o esforço de Schroeder de mostrar que razões epistêmicas podem ter algumas características de razões práticas apenas reforça o contraste entre razões para crer e conhecer e razões para agir, que estou tentando explorar neste trabalho.

Que o estado mental do agente determine quais são suas razões para crer ou intencionar e que essas razões sejam reguladas por normas epistêmicas não quer dizer que ele não possa agir por qualquer outra razão. Casos de acrasia (nos quais o sujeito crê ou intenciona uma coisa e faz outra) acontecem corriqueiramente no âmbito da ação e não parecem envolver qualquer tipo de irracionalidade. ${ }^{30}$ Como escreve Engel, "embora possa haver

\footnotetext{
$3^{\circ}$ Alguns autores, como Christopher Hookway (2001), sustentam que aceitar conscientemente uma proposição, enquanto também se aceita que é errado epistemicamente aceitá-la, pode ser um tipo de acrasia epistêmica. Porém, neste caso, não como um problema do processo de formação de crença ou do julgamento reflexivo ou inferencial, mas como um problema da ação ou da deliberação sobre o que fazer. Concordo com essa visão, mas discordo que esse tipo de acrasia seja epistêmico. Isto porque a estrutura das normas que governam a investigação e a deliberação - particularmente a atitude de aceitar uma proposição a título de investigação - é diferente da estrutura das normas que se aplicam aos estados epistêmicos básicos de crença e conhecimento. É importante notar também que a acrasia é basicamente um problema de motivação, de não se ter a motivação apropriada. Estes casos sugerem que entender e aceitar uma proposição que expressa o meu compromisso com uma norma não é suficiente para me motivar a agir de acordo com ela. Porém, ter uma motivação para agir é diferente de ter uma motivação para crer, julgar, inferir ou conhecer. A ideia de que possa haver motivação epistêmica genuína, de que sejamos motivados diretamente por um desejo desinteressado pela verdade, por exemplo (Sosa 2011), é problemática em vários sentidos. Por outro lado, não há dificuldade de vermos como podemos ser motivados genuinamente a agir por qualquer desejo, incluindo o desejo
} 
razões erradas para crenças e outros estados epistêmicos, não há razões erradas para ações” (Engel 2013: 160). Ou seja, qualquer razão (sendo uma razão que possa fazer parte como premissa em um silogismo prático) pode ser boa para a ação, inclusive razões epistêmicas.

\section{Conclusão}

Sugeri neste trabalho que não há como se falar de agência sem considerar a teoria da ação a que estamos nos referindo. Mostrei também que modelo padrão de ação na literatura é um que concebe a ação em termos de intencionalidade e que explica a intencionalidade em termos de causação pelos estados mentais do agente e eventos. E que se consideramos seriamente este modelo, veremos que a noção de agência epistêmica - a ideia de que possamos ser ativos em relação aos estados epistêmicos básicos de crença e conhecimento - só se justifica em um sentido indireto. $\mathrm{O}$ fato de tomarmos várias decisões e ações para alcançar metas epistêmicas (verdade e conhecimento) e para promover o que alguns chamam de valores puramente epistêmicos (Percival 2002) não quer dizer que a crença ou conhecimento que resulta dessas ações seja uma forma de ação. A ação epistêmica, se houver, será indireta, como ocorre tipicamente no âmbito da investigação, que envolve uma sequência de deliberações práticas com o intuito de estabelecer a verdade sobre $p$ e gerar conhecimento.

Argumentei que há diferenças estruturais cruciais - causais e normativas - entre os estados epistêmicos de crer, julgar reflexivamente, inferir e conhecer e o estado, seja ele qual for, de agir por razões. Se respeitarmos estas diferenças, veremos que o tópico agência epistêmica só nos interessa quando questões práticas estão em jogo. Para sermos agentes epistêmicos, se é que o somos, precisamos ser antes - ou ao mesmo tempo, como afirma Michael Lynch (2013) - agentes práticos. E agentes práticos, redundância à parte, são criaturas movidas por razões práticas. O fato de os compromissos que manifestamos em nossas ações serem eventualmente

pela verdade. Só que, neste caso, não estamos mais falando de motivação epistêmica, mas de motivação prática, como ocorre tipicamente quando investigamos ou deliberamos sobre a verdade de uma proposição. Assim, a acrasia que ocorre no âmbito da investigação e da deliberação, que são atividades práticas orientadas para a verdade, envolve a mesma fraqueza da vontade de quando decidimos que não é bom fazer determinada coisa e a fazemos mesmo assim. Por exemplo: eu sei, todas-as-coisas-consideradas, que eu deveria pesquisar outras fontes antes de aceitar uma tese (proposição) como verdadeira; eu exibo esse compromisso em meu comportamento (sou um bom pesquisador), mas eu nem sempre faço isso. 
epistêmicos - envolvem metas e princípios epistêmicos - não muda a natureza da agência. Assim, o modo de defendermos racionalmente nossos compromissos epistêmicos, que revelam nossa capacidade de agir de forma epistemicamente correta, é o mesmo de quando defendemos qualquer compromisso. ${ }^{31}$ Mas se tudo que podemos oferecer para defender nossa agência epistêmica são razões práticas, qual é ainda o sentido de falarmos de agência epistêmica?

\section{Referências}

ALSTON, W. The reliability of sense perception. Ithaca, NY: Cornell University Press, 1993.

ANSCOMBE, G. E .M. Intention, Oxford: Basil Blackwell, 1957.

AUDI, R. 'Acting for Reasons,' Philosophical Review, 95(4), p. 511-46, 1986.

BRATMAN, M. Intention, Plans, and Practical Reason. Cambridge, MA: Harvard University Press, 1987.

BROOME, J. Rationality through reasoning. Oxford: Wiley Blackwell, 2013.

BROWN, J. 'Subject-Sensitive Invariantism and the Knowledge Norm for Practical Reasoning." Nous, 42, p. 167-89, 2008.

CHISHOLM, R. 'Human Freedom and the Self,' The Lindley Lectures, Department of Philosophy, University of Kansas; reprinted in Free Will, $2^{\text {nd }}$ edition, G. WATSON (ed.), Oxford: Oxford University Press, 2003, p. 26-37, 1964.

CLIFFORD, W. K. 'The ethics of belief,' in T. Madigan, (ed.), The ethics of belief and other essays, Amherst, MA: Prometheus, 70-961877 [1999].

DAVIDSON, D. 'Actions, Reasons, and Causes,' reprinted in Davidson 1980, p. 3-20, 1963.

. 'Mental Events,' in L. FOSTER and W. SWANSON (eds.) Experience and Theory. Humanities Press, p. 79-101, 1970.

. 'Freedom to Act,' reprinted in Davidson 1980, p. 63-81, 1973.

. Essays on Actions and Events, Oxford: Clarendon Press, 1980.

\footnotetext{
${ }^{31}$ De acordo com Lynch, usar razões epistêmicas para defender nossos compromissos com certos princípios epistêmicos fundamentais, como sendo métodos confiáveis (verdadeiros) de geração de evidência, leva invariavelmente a um tipo familiar de circularidade epistêmica, apontado especialmente por William Alston (ver Alston 1993). Por outro lado, ele nota que parece não haver qualquer dificuldade de justificarmos esses princípios com valores objetivos práticos, como acurácia, adaptabilidade, alcance público etc. (Lynch 2013: 355-6).
} 
564 | Veritas | Porto Alegre, v. 62, n. 3, set.-dez. 2017, p. 540-565

ENGEL, P. 'Is Epistemic Agency Possible?,' Philosophical Issues, 23, p. 157-178, 2013.

FELDMAN, R. 'The Ethics of Belief', Philosophy and Phenomenological Research LX, p. 667695, 2000.

FOLEY, R. 'Evidence and reasons for belief,' Analysis, 51, p. 98-102, 1991. Working Without a Net. Oxford: Oxford University Press, 1993.

GINET, C. On Action, Cambridge: Cambridge University Press, 1999.

GOLDMAN, A. A Theory of Human Action. Princeton University Press, 1970.

HAWTHORNE, J. and STANLEY, J. 'Knowledge and action,' The Journal of Philosophy, 105, p. 571-90, 2008.

HETHERINGTON, S. How To Know: A Practicalist Conception of Knowledge. Malden, MA: Wiley-Blackwell, 2011.

.Skeptical Challenges and Knowing Actions,' Philosophical Issues, 23, Epistemic Agency, p. 18-39, 2013.

HOOKWAY, C. 'Epistemic Akrasia and Epistemic Virtue', in A. FAIRWEATHER and L. ZAGZEBSKI (eds.) Virtue Epismology: Essays on Epistemic Virtue and Responsibility. Oxford University Press, p. 178:99, 2001.

HYMAN, J. 'How Knowledge works,' The philosophical Quarterly, 49 (19), p. 433-451, 1999.

JAMES, W. The Will to Believe and Other Essays in Popular Philosophy, New York: Longmans, Green, and Co, p. 1-25, 1896 (2012).

KAVKA, G. 'The Toxin Puzzle,' Analysis, 43, p. 33-6, 1983.

LITTLEJOHN, C. 'The Unity of Reason,' in C. LITTLEJOHN and J. TURRI (eds.) Epistemic Norms: New Essays on Action, Belief, and Assertion. Oxford University Press, p. 135-54, 2014 .

LOWE, E. J. Personal Agency: The Metaphysics of Mind and Action, Oxford: Oxford University Press, 2008.

LYNCH, M. 'Epistemic Commitments, Epistemic Agency and Practical Reasons,' Philosophical Issues, 23, p. 343-62, 2013.

MELDEN, A. I. Free Action, London: Routledge and Kegan Paul, 1961.

MELE, A. Motivation and Agency, Oxford: Oxford University Press, 2003.

NAGEL, J. 'Knowledge as a Mental State', Oxford Studies in Epistemology, 4, p. 275-310, 2013.

O’BRIEN, L. Self-Knowing Agents. Oxford: Oxford University Press, 2007. 
D. Engel - O que é agência epistêmica, afinal? | 565

PARFIT, D. On What Matters. Oxford: Oxford Universisty Press, 2011.

PERCIVAL, P. 'Epistemic Consequentialism,' The Aristotelian Society Supplementary Volume, 76 (1), p. 121-151, 2002.

RYLE, G. The Concept of Mind. London: Hutchinson, 1949.

SCANLON, T. What we owe to each other, Harvard: Harvard University Press, 1998

SCHLOSSER, M. E. 'Agency,' Stanford Encyclopedia of Philosophy (first Edition), E. N. Zalta (ed.), URL: http://plato.stanford.edu/entries/agency/., 2015.

SCHROEDER, M., 'The Ubiquity of State-Given Reasons,' Ethics, 122( 3), p. 457-488, 2012.

SEHON, S. Teleological Realism: Mind, Agency, and Explanation, Cambridge, MA: MIT Press, 2005 .

SETIYA, K. 'Epistemic Agency: Some Doubts,' Philosophical Issues, 23 (1), p. 179-198, 2013.

SIDGWICK, H. The Methods of Ethics. London: MacMillan, 1874.

SOSA, E. ‘Knowing Full Well. Princeton: Princeton University Press, 2011.

STANLEY, J. and WILLIAMSON, T. 'Knowing how.' The Journal of Philosophy, 98, p. 41144, 2001.

SUIKKANEN, J. 'Introduction”, in J. SUIKKANEN and J. COTTINGHAM (eds.) Essays on Derek Parfit's On What Matters, Willey-Balckwell, p. 1-20, 2009.

TAYLOR, R. Action and Purpose, Englewood Cliffs: Prentice-Hall, 1966.

VELLEMAN, D. 'What Happens when Someone Acts?,' Mind, 101, p. 461-481, 1992.

. The possibility of Practical Reason, Oxford, Oxford University Press, 2000.

WILLIAMSON, T. Knowledge and its limits. Oxford: Oxford University Press, 2000.

. 'Contextualism, Subject-Sensitive Invariantism, and Knowledge of Knowledge,' Philosophical Quarterly. 55, p. 213: 35, 2005.

\section{Endereço postal:}

Programa de Pós-graduação em Filosofia da PUCRS

Av. da Ipiranga, 6681, prédio 5 - Porto Alegre, RS, Brasil

Data de recebimento: 31-08-2017

Data de aceite: 05-12-2017 